\title{
Social Cohesion Strengthens Compliance With COVID-19 Restrictions: Evidence From a Longitudinal Study
}

Islam Borinca

University of Limerick

siobhan Griffin

University of Limerick

Cillian McHugh

University of Limerick

Daragh Bradshaw

University of Limerick

Sarah Jay

University of Limerick

Jenny Roth

University of Limerick

Mike Quayle

University of Limerick

Grace McMahon

University of Limerick

Alastair Nightingale

University of Limerick

Megan Ryan

University of Limerick

Aoife Marie Foran

University of Limerick

Rose Galvin

University of Limerick

Eavan G. Muldoon

Mater Misericordiae University Hospital

Orla Muldoon ( $\nabla$ orla.muldoon@ul.ie )

University of Limerick 
Keywords: COVID-19, national trust, compliance, social cohesion

Posted Date: October 14th, 2021

DOl: https://doi.org/10.21203/rs.3.rs-923189/v1

License: (a) (i) This work is licensed under a Creative Commons Attribution 4.0 International License. Read Full License 


\section{Abstract}

Background: Although citizens in countries worldwide took coordinated steps to support collective public health during the COVID-19 pandemic, the processes that encourage citizens to adhere with COVID-19 restrictions are not fully understood.

Method: A three-wave study with a sample of Irish citizens $\left(N_{\text {Wave } 1}=1,800\right)$ was conducted during the COVID-19 pandemic in order to examine the effect of national trust on individual and normative compliance with COVID-19 restrictions directly or indirectly through social cohesion. Two longitudinal mediation models were tested.

Results: In the first model, national trust significantly and positively predicted social cohesion, which in turn significantly and positively predicted personal compliance with COVID-19 restrictions. The second model showed a similar pattern, whereby national trust significantly predicted social cohesion, which in turn predicted normative compliance with the restrictions.

Conclusions: National trust and social cohesion both work to promote adherence to COVID19 guidelines.

\section{Background}

Managing the COVID-19 pandemic is fundamentally about managing human behavior. The measures implemented worldwide to control the spread of Severe Acute Respiratory Syndrome Coronavirus 2 (SARS-CoV-2) proscribe health behaviors: limiting social contacts, wearing protective masks, and maintaining social distance. And while behaviour change is required individually, it also needs to be coordinated so that everyone in a given community or nation acts in ways that supports wider public health. Indeed, the COVID-19 pandemic has brought into sharp relief the importance of collective coordination of efforts to suppress the disease (Muldoon et al., 2021). To achieve this, many national governments have acted to encourage behavioral changes (Gette et al., 2021; Manikandan, 2020) with more and less success. An important driver of willingness to engage with advice is peoples trust in government. In a recent systematic review, Muldoon et al. (2021) have highlighted national trust as a central factor of vaccine uptake. In fact, survey data revealed that those who trust health authorities are more likely to engage with COVID-19 public health advice (Henderson, 2021). Social cohesion is doubtlessly a second important driver of collective beliefs and behaviors (Jewett et al., 2021). In particular, during pandemics, collective awareness and unity are argued to influence individuals' motivation to comply with restrictions put in place to counter the spread of the disease (Tabernero et al., 2020). Empirically, others have demonstrated that a sense of cohesion has significantly influenced the development of supportive and prosocial behaviors, throughout the COVID-19 pandemic (Boyd \& Martin, 2020; Igwe et al., 2020; Lau et al., 2021). In this paper, we extend that work and bring those two sets of findings together by considering the potential effect trust in national government on social cohesion and perceived normative and personal compliance with COVID-19 restrictions during the first six months of the pandemic. 


\section{National Trust's Effect on Compliance with COVID-19 Restrictions}

Trust in systems, in institutions, and in authority, as well as in conventions, practices, and norms, is essential for the functioning and maintenance of formal and institutional norms as well as norm-related roles and behaviors (Falcone et al., 2013). In particular, research has shown that trust in authorities is positively related to the adoption of recommended or mandated preventive behaviors during past pandemics (Siegrist \& Zingg, 2014). Prati et al. (2011) found, for example, that Italian citizens who trusted their health ministry were more likely to follow recommended health guidelines during the novel influenza A (H1N1; swine flu) pandemic than citizens who did not trust the ministry. In agreement with those findings, studies conducted during the same pandemic, both in the Netherlands and in the United States, demonstrated that trust in the government was positively related to being vaccinated (e.g., Quinn et al., 2009; van der Weerd et al., 2011). Blair et al. (2017) also demonstrated that trust in the government was positively associated with compliance with government-mandated social distancing measures during the Ebola epidemic in Liberia.

Likewise, research on collective trust has shown that the more trust citizens have in their community, the more that social cohesion, integration, and stability are likely to occur (Newton et al., 2018; Phillips \& Berman, 2008), all of which facilitate active engagement and connection with others (Delhey \& Newton, 2003; Newton et al., 2018). Collective trust has also been linked to cooperative, altruistic, and healthy behaviors (Delhey, 2014; Lindström, 2005, 2008; Uslaner, 2002). For instance, high levels of collective trust have been associated with non-smoking, adequate sleep, and less alcohol consumption (Nieminen et al., 2013; Poortinga, 2006). Research conducted during the COVID-19 pandemic has additionally shown that specific types of national political trust (i.e., confidence in the health care system) predicted a longerlasting social distancing response (Chan et al., 2020; Woelfert \& Kunst, 2020). Furthermore, crosssectional data has demonstrated that trust in institutions (health care, COVID-19 committee) predicted greater adherence to social distancing measures in Slovakia (Caplanova et al., 2021), and across 23 countries trust in governments was associated with greater engagement in COVID-19 mitigation behaviors (Pagliaro et al., 2021). However, despite researchers' calls for special attention to national trust and social cohesion during the COVID-19 pandemic (Ayalon, 2021; Jewett et al., 2021), no research has examined the longitudinal relationships of national trust (i.e., trust in government) on compliance with COVID-19 restrictions, either at the individual or collective level, via social cohesion over time.

Because public trust appears to predict both social cohesion and compliance with COVID-19 restrictions, and social cohesion predicts motivation to comply with COVID-19 restrictions and increase willingness for prosocial behaviors), it is reasonable to expect that trust will also predict COVID-19 restrictions through social cohesion. As such, this perspective is consistent with earlier research indicating that social cohesion explains the relationship between social determinants (such as mobility) and pro-health behaviors and healthy lifestyle choices (Cho, 2020; Kingsbury et al., 2020). Therefore, in the present study, we examined the proposition that trust predicts social cohesion, and that social cohesion predicts both personal and normative compliance with COVID-19 restrictions. 


\section{The current study}

In 2020, nearly 50 million people worldwide were tested positively with COVID-19. The pandemic left governments in a state of extreme uncertainty that forced them to make tough trade-offs to manage the fallout for public health, the economy, and society in general. By spring 2020, more than half of the world's population had been subjected to a lockdown accompanied by strict containment measures (Allain-Dupré et al., 2020). In Ireland, where our study was undertaken, government agencies at the regional, municipal, and local levels have been at the forefront of crisis management (De Bruin, Monaghan, \& Yakut, 2020). In the current study we aimed to examine whether trust in the actions of national institutions can facilitate social cohesion and whether such cohesion can influence individuals' personal compliance with COVID-19 as well as their perceptions of normative compliance with such behaviors. Therefore, in our longitudinal study, we tested three hypotheses: namely, that trust in the national government predicts social cohesion $(\mathrm{H} 1)$ and that social cohesion predicts personal behaviors $(\mathrm{H} 2 \mathrm{a})$ and normative perception of compliance with COVID-19 restrictions $(\mathrm{H} 2 \mathrm{~b})$.

\section{Method}

\section{Participants and Procedure}

The sample consisted of 1,800 people residing in the Republic of Ireland at Time 1 (mean age $=39.10$ years, $S D=14.65$ ). Wave 1 of data collection was conducted in April 7-19, 2020, approximately a month after the Irish government issued recommendations to curb the spread of COVID-19. A link to the survey, hosted on Qualtrics, was shared on various social media platforms, including Facebook and Twitter. Participants were asked to create a unique identification code (i.e., provide the first two letters of their mother's maiden name, first two digits of their year of birth, and the first two letters of their town of birth) to be used to link their responses across subsequent waves of data collection if they chose to provide an email address in order to be contacted for further data collection. Of all prospective participants who provided contact details for further data collection, 218 participated at Time 2 (June 2020) and 122 at Time 3 (October 2020). Appropriate ethics approvals for research involving humans were obtained.

\section{Measures}

\section{Predictor Variables}

National Trust was measured with a two-item scale adapted from (Wellcome Trust, 2019) at each of the three time points. Participants were asked to rate the extent that they trust "The national government in this country" (reversed) and "The national government response to COVID-19 in this country" (reversed). Items were rated on a 4-point response scale, ranging from 1 (a lot) to 4 (not at all); higher scores indicated greater national trust.

Police Trust. In order to assess police trust, three items were used across three time points. Participants indicated the degree to which they trusted that police actions were enforcing health advice during the 
COVID-19 pandemic (e.g., "By enforcing the health advice on COVID-19 such as staying at home and maintaining physical distance, the police are acting in the best interests of all communities").

Participants rated the items on a 7-point response scale, ranging from 1 (strongly disagree) to 7 (strongly agree). Higher scores indicated greater police trust. Because the results for police trust demonstrated a pattern similar to national trust, they are shown in the Supplementary Materials.

\section{Mediator}

Social Cohesion. In order to assess social cohesion, five items were used (e.g., "The crisis taught us that we are there for each other" and "As a result of the crisis, we are more sensitive nationally to the needs of others") across three time points on a 7-point response scale, ranging from 1 (strongly disagree) to 7 (strongly agree). Higher scores indicated greater social cohesion.

\section{Outcomes}

Personal Compliance with COVID-19.[1]Personalbehaviors to prevent the spread of the virus were assessed with a nine-item scale at Time 1 and with a 10-item scale at Times 2 and 3, both adapted from research assessing protective behaviors during the severe acute respiratory syndrome (SARS) pandemic (e.g., Brug et al., 2004; Cheng \& Ng, 2006). Behaviors included handwashing, social distancing (e.g., not visiting family and friends), adhering to the $2-\mathrm{km}$ exercise limit, and avoiding public places. Items were rated on a 7-point Likert scale, ranging from 1 (strongly disagree) to 7 (strongly agree); higher scores indicated higher compliance with the prescribed behaviors.

Normative Compliance with COVID-19. A similar scale was used to gauge normative compliance, which participants used to rate how much they thought that others were respecting COVID-19 restrictions (e.g., "Others have worn a face mask in a public place" and "Others have avoided public places"). The scale had nine items at Time 2 and 10 items at Times 2 and 3, and at both times, the response scale ranged from 1 (strongly disagree) to 7 (strongly agree). Higher scores indicated more normative compliance with COVID-19 restrictions.

\section{Analytic Approach}

We tested our longitudinal mediation hypotheses by using Hayes's PROCESS Macro (2018; Template 4) in the SEM software AMOS (v. 25). The predictor variable was national trust (T1), the mediator was social cohesion (T2), and the outcome variables were personal compliance and normative compliance (both T3). In addition, personal and normative compliance at T1 were also included in their respective analyses, such that changes over time in the mediator and dependent variable were apparent. Table 1 presents the means, standard deviations, and Cronbach's alphas for all variables at the three time points.

\section{Results}

\section{Preliminary Data Analyses}


Before analyzing any of the data, we conducted analyses to understand the data that were missing. Missing data analysis showed the data were not missing completely at random (MCAR; Little's MCAR $\chi^{2}=$ $1269.661, d f=.85, p<.001)$; in other words, evidence suggests that data were missing based on certain patterns (Asendorpf et al., 2014; Newman, 2014). To examine whether the data obtained could be used to predict patterns of missingness and therefore the missing data, we conducted a series of $t$ tests. In particular, the $t$ tests examined whether participants who dropped out of the study after Time $1(N=$ $1,592)$ and Time $2(N=96)$ systematically differed from those who completed the questionnaire at all three time points in relation to the five constructs under study. Comparing participants who dropped out at Time 1 and matched participants revealed two significant differences; participants who dropped out at Time 1 reported more national trust and less compliance with personal behaviors than matched participants. The comparison of participants who dropped out at Time 2 and matched participants revealed only one significant difference, namely that participants who dropped out at Time 2 reported less police trust than matched participants (see Supplementary Materials). Given those patterns of missingness and to maintain the representativeness of the sample, all respondents who had data available at Time 1 and Time 2 were included in the final analyses of the longitudinal SEM mediation, irrespective of whether they had dropped out after Time 1 or Time 2, using the full information maximum likelihood method. In SEM analyses, full information maximum likelihood allows for the generation of more accurate parameter estimates for which partly recorded (or missing) data may be considered to be missing at random (Enders, 2001; Newman, 2003; Schafer \& Graham, 2002; Stevens, 2002; Swart et al., 2011).

\section{National Trust's Indirect Effect on Personal Compliance via Social Cohesion}

National trust (T1) significantly and positively predicted social cohesion (T2), $\beta=.1 .16, p<.001$, and social cohesion (T2) was, in turn, significantly and positively associated with personal compliance (T3), $\beta=.57, p<.001$. Supporting our hypothesis, the indirect effect of national trust on personal compliance via social cohesion was significant, $\beta=.67(95 \% \mathrm{Cl} . .56, .78)$. The model is summarized in Figure 1 .

\section{Alternative Models}

We also explored two theoretically plausible alternative models for explaining the relationships between those variables. First, we explored personal compliance ( $\mathrm{T} 1)$ as the predictor variable and national trust (T3) as the outcome variable, with social cohesion (T2) as the mediating variable. That analysis revealed a nonsignificant indirect effect, $\beta=2.51$ (95\% Cl: $-10.1,14.6)$.

Next, we explored trust (T1) as the predictor variable, personal compliance (T2) as the mediating variable, and social cohesion (T3) as an outcome variable. Despite results indicating that the association between trust and personal compliance was not significant, $\beta=.005, p=.887$, the indirect effect was significant, $\beta$ $=.02(95 \% \mathrm{Cl} . .001, .004)$.

Those results support our overall hypothesis that social cohesion partly accounts for the relationship between national trust and personal compliance with COVID-19 restrictions. 
Nevertheless, further results indicated that social cohesion could be considered either a mediator or the outcome of the predicted effect. Because we cannot conclude with certainty that social cohesion played only a mediating role in our model, further research is required in order to provide more cogent evidence supporting the hypothesis that social cohesion accounts for the investigated effects.

\section{National Trust's Indirect Effect on Normative Compliance via Social Cohesion}

National trust (T1) significantly and positively predicted social cohesion (T2), $\beta=1.16, p<.001$, which was in turn significantly associated with normative compliance (T3), $\beta=.49, p<.001$. Supporting our hypothesis, national trust's indirect effect on normative compliance via social cohesion was significant, $\beta$ $=.58(95 \% \mathrm{Cl} . .48, .67)$. The model is summarized in Figure 2 .

\section{Alternative Models}

Again, we explored two theoretically plausible alternative models for explaining the relationships between those variables. First, we explored normative compliance ( $\mathrm{T} 1)$ as the predictor variable and national trust (T3) as the outcome variable, with social cohesion (T2) again as the mediating variable. The analysis revealed a nonsignificant indirect effect, $\beta=.07(95 \% \mathrm{Cl}:-1.84,0.09)$.

Next, we explored trust (T1) as the predictor variable, normative compliance (T2) as the mediating variable, and social cohesion (T3) as an outcome variable. Even though results indicated that the association between trust and normative compliance was not significant , $\beta=.006, p=.877$, the indirect effect was significant, $\beta=.03$ (95\% Cl: .002, .005).

Those results support our overall hypothesis that social cohesion partly accounts for the relationship between trust and normative compliance. Nonetheless, additional findings suggest that social cohesion can be considered as either a mediator or an outcome of the predicted effect. We cannot conclude with certainty that social cohesion played only a mediating role in our model; therefore, additional research is required to provide more compelling evidence supporting the hypothesis that social cohesion accounts for the investigated effects.

\section{Discussion}

Our longitudinal study showed that national trust was positively associated with personal and normative compliance with COVID-19 restrictions via social cohesion, at least in an Irish sample. The observed effects emerged while controlling for baseline levels of personal and normative compliance with COVID19 restrictions (time 1), which increases our confidence in the direction of the hypothesized effects. More specifically, national trust positively and significantly predicted social cohesion, which in turn positively and significantly predicted personal and normative compliance with the restrictions. Put differently, the greater the trust in the national government's approach to the COVID-19 pandemic, the more that individuals felt close, understanding, and sensitive to their ingroup members, which consequently 
affected how they have behaved during pandemic, as well as how they perceived the behavior of their ingroup members.

\section{Theoretical Implications}

The evidence presented here highlights the importance of intragroup processes, including inclusive, national social cohesion, during difficult times such as the COVID-19 pandemic. In our analysis, national trust seemed to facilitate inclusive, national social cohesion, which is especially relevant to the response to the pandemic. Moreover, those results align with previous findings highlighting that greater trust in government promotes compliance with health policies, including measures relating to quarantining, testing, and restrictions on mass gatherings (Van Bavel et al., 2020). Indeed, those insights corroborate documented experiences with past epidemics, including the Ebola outbreak in West Africa in 2014-2016 (Blair et al., 2017; Morse et al., 2016) and the SARS, avian influenza, and H1N1 pandemics (Siegrist \& Zingg, 2014).

To the extent of our knowledge, our longitudinal study marks the first to demonstrate the mediating role of inclusive, national social cohesion in the relationship between national trust and COVID-19 compliance. The findings are consistent with testimonies that the COVID-19 pandemic has brought communities closer together, because it has made them more aware about the consequences and connected them to each other (e.g., Holzwarth, 2020). The findings are also consistent with the proposition that investing in national, inclusive social cohesion contributes to the formation of stronger,

more connected, and more open communities that are better prepared to cope with crisis situations (Lalot et al., 2021).

The understanding suggested by our results can be explained by research in psychology, which has shown, for example, that acute stress may generate greater cooperative, social, and friendly behaviors Von Dawans et al. (2012), for example, had participants undergo a stressful situation (i.e., a public speaking activity followed by solving math equations before an audience), and subsequently play economic games that required them to make decisions about trust, sharing, and punishment. The researchers found that after performing the stressful tasks, participants were more trusting of others, behaved in more trustworthy ways, and tended to be more cooperative and prosocial. To put it another way, during difficult experiences, people appear to be willing to trust and connect with one another on a human level, and thus act decently.

\section{Practical Implications}

The findings have practical implications for managing the COVID-19 pandemic and other future threats involving contagious diseases. For one, they emphasize that national institutions (i.e., governments) and their responses (i.e., police actions) are crucial to promoting individuals' awareness that they learn from the pandemic, be more supportive of members of their community, and thus individually and collectively observe COVID-19 restrictions. 
Beyond that, the findings emphasize the need for governments to value public trust in institutions, which should be actively cultivated via consistent, coordinated responses to crises such as the COVID-19 pandemic. Governments should also actively avoid actions that undermine trust, including unexplained changes in policy directions and inequitable applications of rules. Last, for individuals who have low trust in their governments (Yamagishi, 2001), harbor various COVID-19 conspiracies (Gu et al., 2021), and/or believe that the fact that "We are all in this together" has become a cliché during the COVID-19 pandemic (McGuire et al., 2020), it is critical for governments to continue their efforts to protect the health of their populations (Edwards \& Ott, 2021). The government should also pay attention to their methods of public health communication so that they do not create divisions within their nation (Maher et al., 2020), which might result in bias and hostility among the population.

\section{Limitations and Future Directions}

Despite the novelty and importance of our findings, we should acknowledge our research's limitations and propose directions for future studies. First, a notable limitation of our study is that it was conducted in Ireland only. To counter that limitation, future studies should attempt to replicate our findings in different contexts with different populations as a means to test their generality. That effort is particularly important because the COVID-19 pandemic is an unprecedented global crisis.

Second, the large dropout of participants after Wave 1 persisted even after Wave 2, which indicates a high attrition bias. Our longitudinal study also focused only on self-reported measures of personal and normative compliance, meaning that future research should prioritize examining how trust via social cohesion influences actual and/or observed behaviors. Alternatively, experimental and qualitative research could also be useful for understanding people's perceptions of and reactions during the COVID19 pandemic.

Third, our personal and normative compliance measures had a low level of reliability, possibly due to the existence of heterogeneous constructs such as hygiene, physical distancing, and intragroup (social) contact on the scale (Tavakol \& Dennick, 2011). In fact, the reliability was higher when those constructs were examined independently. Even so, to avoid that problem, future research should focus on a particular behavior or construct.

Fourth and last, our mediation analyses also revealed that alternative models could also benefit the examination of the underlying mechanisms between the investigated constructs. Although social cohesion partly accounted for the effect of trust on both personal and normative compliance with COVID19 , our additional analyses showed that normative compliance and personal compliance are also responsible for the effect of trust on social cohesion. Future research should examine that relationship in greater detail.

\section{Conclusions}


To contain the spread of COVID-19 across the globe, personal protective measures have been implemented, including social distancing, handwashing, and avoiding public places. Those measures are only effective, however, if people personally and collectively adhere to them. The results of our longitudinal study demonstrate the crucial role that national institutions have played in bringing people together during the COVID-19 pandemic and in enhancing their compliance with restrictions to curb the spread of the disease. National institutions' persistence in monitoring threatening situations such as the COVID-19 pandemic appears to facilitate national, inclusive social cohesion, which is pivotal to public health responses to pandemics.

\section{Declarations}

\section{Ethical approvals}

The research conducted was approved by the University of Limerick, Faculty of Education and Health Sciences Research Ethics Committee (Ref: 2020_02_03_EHS). This ethical approval is guided by and is complaint University of Limerick Research Ethics Guidance which is fully complaint with The European Code of Conduct for Research Integrity.

Informed consent was obtained from all participants.

\section{Consent for publication}

Not applicable as no human identity revealing data used in the study

\section{Availability of data and materials}

Data supporting the results reported in the article are available from the corresponding author.

The survey and associated measures are registered in the open science framework at https://osf.io/y64gs/?view_only=1778d8bde8614aca818f90e1c60891b6

\section{Competing interests}

The authors have no competing interests to declare.

\section{Funding}

We wish to acknowledge funding (COV19-2020-120) from a joint initiative of the Health

Research Board and the Irish Research Council in response to the COVID19 pandemic and the European Research Council 884927.

\section{Authors Contributions:}

Islam Borinca analysed the data and drafted the paper. 
Siobhan Griffin researched and selected the survey measures related to adherence and commented on all stages of the analysis and write up.

Cillian McHugh researched and selected the survey measures related to normative adherence and commented on all stages of the analysis and write up.

Daragh Bradshaw managed recruitment of participants and offered dffedback on analysis and write up.

Sarah Jaydeveloped research and selected the survey measures related to socail cohesion.

Jenny Rothmanaged the open science website and pre-registered the study.

Mike Quayle

Grace McMahon offered feedback on the analysis and the write up of the manuscript.

Alastair Nightingaleoffered feedback on the analysis and the write up of the manuscript

Megan Ryanresearched and developed the survey measure of trust.

Aoife Foranmanaged the online survey at set up, administration and cleaned the data

Rose Galvinwas involved in the conceptualization of the research and offered feedback on manuscript and public health expertise

Eavan G. Muldoonwas involved in the conceptualization of the research and offered feedback on manuscript and public health expertise

*Orla T. Muldoon managed the project from inception, securing funding, integrating team ideas offering feedback and editing on drafts.

\section{Acknowledgements}

Funding from the Health Research Board and the Irish Research Council.

\section{References}

1. Al-Omoush, K. S., Orero-Blat, M., \& Ribeiro-Soriano, D. (2021). The role of sense of community in harnessing the wisdom of crowds and creating collaborative knowledge during the COVID-19 pandemic. Journal of Business Research, 132(1), 765-774. doi:org/10.1016/j.jbusres.2020.10.056

2. Allain-Dupré, D., Chatry, I., Michalun, V., \& Moisio, A. (2020). The territorial impact of COVID-19: Managing the crisis across levels of government. Retrived from [https://www.oecd.org/coronavirus/policy-responses/the-territorial-impact-of-covid-19-managing-thecrisis-across-levels-of-government-d3e314e1/]. OECD. 
3. Asendorpf, J. B., Van De Schoot, R., Denissen, J. J., \& Hutteman, R. (2014). Reducing bias due to systematic attrition in longitudinal studies: The benefits of multiple imputation. International Journal of Behavioral Development, 38(5), 453-460. doi:org/10.1177/0165025414542713

4. Ayalon, L. (2021). Trust and compliance with covid-19 preventive behaviors during the pandemic. International Journal of Environmental Research and Public Health, 18(5), 2643. doi:org/10.3390/ijerph18052643

5. Blair, R. A., Morse, B. S., \& Tsai, L. L. (2017). Public health and public trust: Survey evidence from the Ebola Virus Disease epidemic in Liberia. Social Science \& Medicine, 172(1), 89-97. doi:org/10.1016/j.socscimed.2016.11.016

6. Boyd, N. M., \& Martin, E. C. (2020). Sense of community responsibility at the forefront of crisis management. Administrative Theory \& Praxis, 1-13. doi:org/10.1080/10841806.2020.1765288

7. Brug, J., Aro, A. R., Oenema, A., De Zwart, O., Richardus, J. H., \& Bishop, G. D. (2004). SARS risk perception, knowledge, precautions, and information sources, the Netherlands. Emerging Infectious Diseases, 10(8), 1486. doi:org/10.3201/eid1008.040283

8. Caplanova, A., Sivak, R., \& Szakadatova, E. (2021). Institutional Trust and Compliance with Measures to Fight COVID-19. International Advances in Economic Research, 27(1), 47-60. doi:org/10.1007/s11294-021-09818-3

9. Chan, H. F., Brumpton, M., Macintyre, A., Arapoc, J., Savage, D. A., Skali, A., . . Torgler, B. (2020). How confidence in health care systems affects mobility and compliance during the COVID-19 pandemic. PloS One, 15(10), e0240644. doi:org/10.1371/journal.pone.0240644

10. Cheng, C., \& Ng, A. K. (2006). Psychosocial factors predicting SARS-preventive behaviors in four major SARS-affected regions. Journal of Applied Social Psychology, 36(1), 222-247. doi:org/10.1111/j.0021-9029.2006.00059.x

11. Cho, Y. (2020). The association between residential mobility and adolescents' health: The mediating role of neighborhood social cohesion. Journal of Community Psychology, 48(5), 1469-1480. doi:org/10.1002/jcop.22341

12. De Bruin, K. C., Monaghan, E., \& Yakut, A. M. (2020). The environmental and economic impacts of the COVID-19 crisis on the Irish economy: An application of the I3E model. doi:org/10.26504/rs106

13. Delhey, J. (2014). "Trust" in Encyclopedia of quality of life and well-being research. In ed. A. C. Michalos (Dordrecht, Netherlands: Springer), 6743-6747.

14. Delhey, J., \& Newton, K. (2003). Who trusts?: The origins of social trust in seven societies. European Societies, 5(2), 93-137. doi:org/10.1080/1461669032000072256

15. Edwards, F., \& Ott, J. S. (2021). Governments' Responses to the COVID-19 Pandemic. In: Taylor \& Francis.

16. Enders, C. K. (2001). The impact of nonnormality on full information maximum-likelihood estimation for structural equation models with missing data. Psychological Methods, 6(4), 352. doi:org/10.1037/1082-989X.6.4.352 
17. Falcone, R., Castelfranchi, C., Cardoso, H. L., Jones, A., \& Oliveira, E. (2013). Norms and trust. In Agreement Technologies (pp. 221-231): Springer, Dordrecht.

18. Gette, J. A., Stevens, A. K., Littlefield, A. K., Hayes, K. L., White, H. R., \& Jackson, K. M. (2021). Individual and COVID-19-Specific Indicators of Compliance with Mask Use and Social Distancing: The Importance of Norms, Perceived Effectiveness, and State Response. International Journal of Environmental Research and Public Health, 18(16), 8715. doi:org/10.3390/ijerph18168715

19. Gu, F., Wu, Y., Hu, X., Guo, J., Yang, X., \& Zhao, X. (2021). The Role of Conspiracy Theories in the Spread of COVID-19 across the United States. International Journal of Environmental Research and Public Health, 18(7), 3843. doi:org/10.3390/ijerph18073843

20. Hayes, A. F. (2018). Introduction to mediation, moderation, and conditional process analysis: A regression-based approach: Guilford publications, New York, NY.

21. Henderson, E. (2021). APPC survey: Public trust in top U.S. health agencies and Fauci holds steady. News Medical Life Sciences. Retrieved from https://www.news-medical.net/news/20210720/APPCsurvey-Public-trust-in-top-US-health-agencies-and-Fauci-holds-steady.aspx

22. Holzwarth, A. (2020). The global pandemic has brought us together. Retrieved from https://pattern.health/articles/covid-19-pandemic-brought-us-together

23. Igwe, P. A., Ochinanwata, C., Ochinanwata, N., Adeyeye, J. O., Ikpor, I. M., Nwakpu, S. E., . . Nwekpa, K. C. (2020). Solidarity and social behaviour: how did this help communities to manage COVID-19 pandemic? International Journal of Sociology and Social Policy. doi:org/10.1108/IJSSP-07-20200276/full/html

24. Jewett, R. L., Mah, S. M., Howell, N., \& Larsen, M. M. (2021). Social Cohesion and Community Resilience During COVID-19 and Pandemics: A Rapid Scoping Review to Inform the United Nations Research Roadmap for COVID-19 Recovery. International Journal of Health Services, 0020731421997092. doi:10.1177/0020731421997092

25. Kingsbury, M., Clayborne, Z., Colman, I., \& Kirkbride, J. B. (2020). The protective effect of neighbourhood social cohesion on adolescent mental health following stressful life events. Psychological Medicine, 50(8), 1292-1299. doi:org/10.1017/S0033291719001235

26. Lalot, F., Abrams, D., Broadwood, J., Davies Hayon, K., \& Platts-Dunn, I. (2021). The social cohesion investment: Communities that invested in integration programmes are showing greater social cohesion in the midst of the COVID-19 pandemic. Journal of Community \& Applied Social Psychology. doi:org/10.1002/casp.2522

27. Lau, B. H., Chan, C. L., \& Ng, S.-M. (2021). Resilience of Hong Kong people in the COVID-19 pandemic: lessons learned from a survey at the peak of the pandemic in Spring 2020. Asia Pacific Journal of Social Work and Development, 31(1-2), 105-114. doi:org/10.1080/02185385.2020.1778516

28. Lindström, M. (2005). Social capital, the miniaturization of community and high alcohol consumption: a population-based study. Alcohol and Alcoholism, 40(6), 556-562. doi:org/10.1093/alcalc/agh190 
29. Lindström, M. (2008). Social capital and health-related behaviors. In Social Capital and Health (pp. 215-238): Springer.

30. Maher, P., MacCarron, P., \& Quayle, M. (2020). Mapping public health responses with attitude networks: the emergence of opinion-based groups in the UK's early COVID-19 response phase. British Journal of Social Psychology, 59(3), 641-652. https://doi.org/10.1111/bjso.12396

31. Manikandan, N. (2020). Are social distancing, hand washing and wearing masks appropriate measures to mitigate transmission of COVID-19? Vacunas, 21(2), 136. doi:org/10.1016/j.vacun.2020.09.001

32. McGuire, D., Cunningham, J. E., Reynolds, K., \& Matthews-Smith, G. (2020). Beating the virus: an examination of the crisis communication approach taken by New Zealand Prime Minister Jacinda Ardern during the Covid-19 pandemic. Human Resource Development International, 23(4), 361-379. doi:org/10.1080/13678868.2020.1779543

33. Muldoon, O.T., Bradshaw, D., Jay, S., Kinsella, E., Maher, P., Murphy, R., O’Donnell, P., Taafe, C. (in press). Vaccination Roll Out: An Opportunity to Develop and Maintain Trust in Science and Health Care. British Journal of General Practice.

34. Muldoon, O. T., Liu, J. H., \& McHugh, C. (2021). The Political Psychology of COVID-19. Political Psychology. doi.org/10.1111/pops.12775

35. Morse, B., Grépin, K. A., Blair, R. A., \& Tsai, L. (2016). Patterns of demand for non-Ebola health services during and after the Ebola outbreak: panel survey evidence from Monrovia, Liberia. BMJ Global Health, 1(1), e000007. doi:org/10.1136/bmjgh-2015-000007

36. Newman, D. A. (2003). Longitudinal modeling with randomly and systematically missing data: A simulation of ad hoc, maximum likelihood, and multiple imputation techniques. Organizational Research Methods, 6(3), 328-362. doi:org/10.1177/1094428103254673

37. Newman, D. A. (2014). Missing data: Five practical guidelines. Organizational Research Methods, 17(4), 372-411. doi:org/10.1177/1094428114548590

38. Newton, K., Stolle, D., \& Zmerli, S. (2018). "Social and political trust" in The Oxford handbook of social and political trust. ed. E. M. Uslaner (New York, NY, USA: Oxford University Press). In (Vol. 37, pp. 961-976).

39. Nieminen, T., Prättälä, R., Martelin, T., Härkänen, T., Hyyppä, M. T., Alanen, E., \& Koskinen, S. (2013). Social capital, health behaviours and health: a population-based associational study. BMC Public Health, 13(1), 1-11. doi:org/10.1186/1471-2458-13-613

40. Pagliaro, S., Sacchi, S., Pacilli, M. G., Brambilla, M., Lionetti, F., Bettache, K., . . Boza, M. (2021). Trust predicts COVID-19 prescribed and discretionary behavioral intentions in 23 countries. PloS One, 16(3), e0248334. doi:org/10.1371/journal.pone.0248334

41. Phillips, D., \& Berman, Y. (2008). Social cohesion and the sustainable welfare society. National Taiwan University Social Work Journal,16(1), 2-44.

42. Poortinga, W. (2006). Do health behaviors mediate the association between social capital and health? Preventive Medicine, 43(6), 488-493. doi:org/10.1016/j.ypmed.2006.06.004 
43. Prati, G., Pietrantoni, L., \& Zani, B. (2011). A social-cognitive model of pandemic influenza H1N1 risk perception and recommended behaviors in Italy. Risk Analysis: An International Journal, 31(4), 645656. doi:org/10.1111/j.1539-6924.2010.01529.x

44. Quinn, S. C., Kumar, S., Freimuth, V. S., Kidwell, K., \& Musa, D. (2009). Public willingness to take a vaccine or drug under Emergency Use Authorization during the 2009 H1N1 pandemic. Biosecurity and Bioterrorism: biodefense strategy, practice, and science, 7(3), 275-290. doi:org/10.1089/bsp.2009.0041

45. Schafer, J. L., \& Graham, J. W. (2002). Missing data: our view of the state of the art. Psychological Methods, 7(2), 147. doi:org/10.1037/1082-989X.7.2.147

46. Siegrist, M., \& Zingg, A. (2014). The role of public trust during pandemics. European Psychologist, 19(1), 23-32. doi:org/10.1027/1016-9040/a000169

47. Stevens, J. (2002). Outliers and influential data: Our review of the state of the art. Psychological Methods, $7(1), 147-177$. doi:org/10.1037/1082-989X.7.2.147

48. Swart, H., Hewstone, M., Christ, O., \& Voci, A. (2011). Affective mediators of intergroup contact: A three-wave longitudinal study in South Africa. Journal of Personality and Social Psychology, 101(6), 1221. doi:org/10.1037/a0024450

49. Tabernero, C., Castillo-Mayén, R., Luque, B., \& Cuadrado, E. (2020). Social values, self-and collective efficacy explaining behaviours in coping with Covid-19: Self-interested consumption and physical distancing in the first 10 days of confinement in Spain. PloS One, 15(9), e0238682. doi:org/10.1371/journal.pone.0238682

50. Tavakol, M., \& Dennick, R. (2011). Making sense of Cronbach's alpha. International Journal of Medical Education, 2(1), 53. doi:org/10.5116/ijme.4dfb.8dfd

51. Uslaner, E. M. (2002). The moral foundations of trust. Cambridge University Press.

52. Van Bavel, J. J., Baicker, K., Boggio, P. S., Capraro, V., Cichocka, A., Cikara, M., . . Druckman, J. N. (2020). Using social and behavioural science to support COVID-19 pandemic response. Nature Human Behaviour, 4(5), 460-471. doi:org/10.1038/s41562-020-0884-z

53. van der Weerd, W., Timmermans, D. R., Beaujean, D. J., Oudhoff, J., \& Van Steenbergen, J. E. (2011). Monitoring the level of government trust, risk perception and intention of the general public to adopt protective measures during the influenza A (H1N1) pandemic in the Netherlands. BMC Public Health, 11(1), 1-12. doi:org/10.1186/1471-2458-11-575

54. Von Dawans, B., Fischbacher, U., Kirschbaum, C., Fehr, E., \& Heinrichs, M. (2012). The social dimension of stress reactivity: acute stress increases prosocial behavior in humans. Psychological Science, 23(6), 651-660. doi:org/10.1177/0956797611431576

55. Wllecome Trust, W. (2019). Wellcome Global Monitor: how does the world feel about science and health. Retrieved from https://wellcome.ac.uk/reports/wellcome-global-monitor/2019

56. Woelfert, F. S., \& Kunst, J. R. (2020). How political and social trust can impact social distancing practices during COVID-19 in unexpected ways. Frontiers in Psychology, doi:org/10.3389/fpsyg.2020.572966 
57. Yamagishi, T. (2001). Trust as a form of social intelligence. In K. S. Cook (Ed.), Trust in society (pp. 121-147). Russell Sage Foundation. .

\section{Tables}

Table 1 Means $(S D)$ for all investigated variables across the three time points.

\begin{tabular}{lcccccc}
\hline Variables & Time 1 & $\begin{array}{c}\text { Cronbach's } \\
\text { alpha }\end{array}$ & Time 2 & $\begin{array}{c}\text { Cronbach' } \\
\text { s alpha }\end{array}$ & Time 3 & Cronbach's \\
& \multicolumn{5}{c}{ alpha } \\
\hline National trust & 1.85 & .87 & 3.28 & .78 & $2.28(0.74)$ & .86 \\
& $(0.91)$ & & $(0.64)$ & & & \\
Police trust & 3.06 & .89 & 3.16 & .90 & $1.78(0.48)$ & .87 \\
& $(0.75)$ & & $(0.51)$ & & & \\
Social cohesion & 5.07 & .84 & 5.05 & .82 & $4.74(1.12)$ & .73 \\
& $(1.00)$ & & $(0.97)$ & & & .47 \\
Personal & 4.79 & .47 & 5.25 & .40 & $5.44(0.60)$ & .47 \\
compliance & $(0.66)$ & & $(0.73)$ & & & .60 \\
Normative & 4.68 & .56 & 4.53 & .61 & $4.55(0.65)$ & \\
compliance & $(0.74)$ & & $(0.67)$ & & & \\
\hline
\end{tabular}

\section{Supplementary Materials}

Supplementary Materials are not available with this version.

\section{Figures}




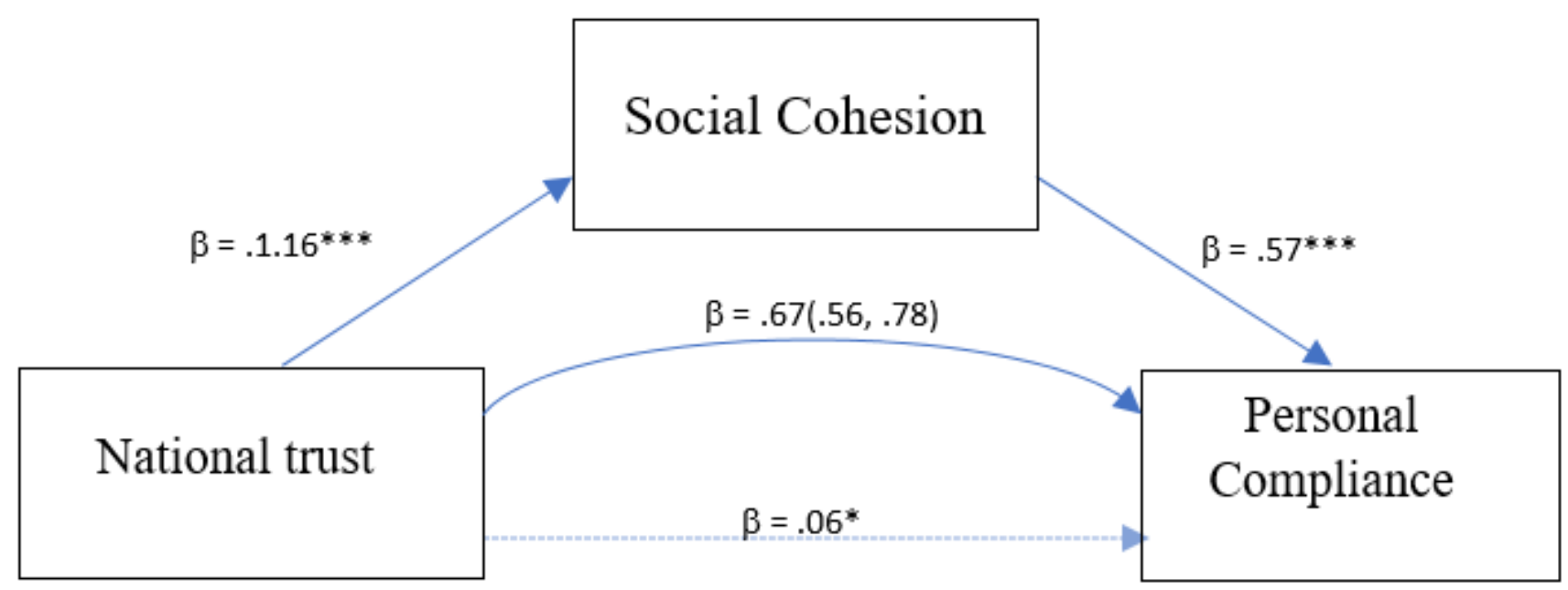

Figure 1

National trust indirectly predicted personal compliance with COVID-19 via social cohesion. Note. The curved arrow in the figure represents the hypothesized indirect effect. The total effect of national trust on personal compliance was $\beta=.74, p=.001$.

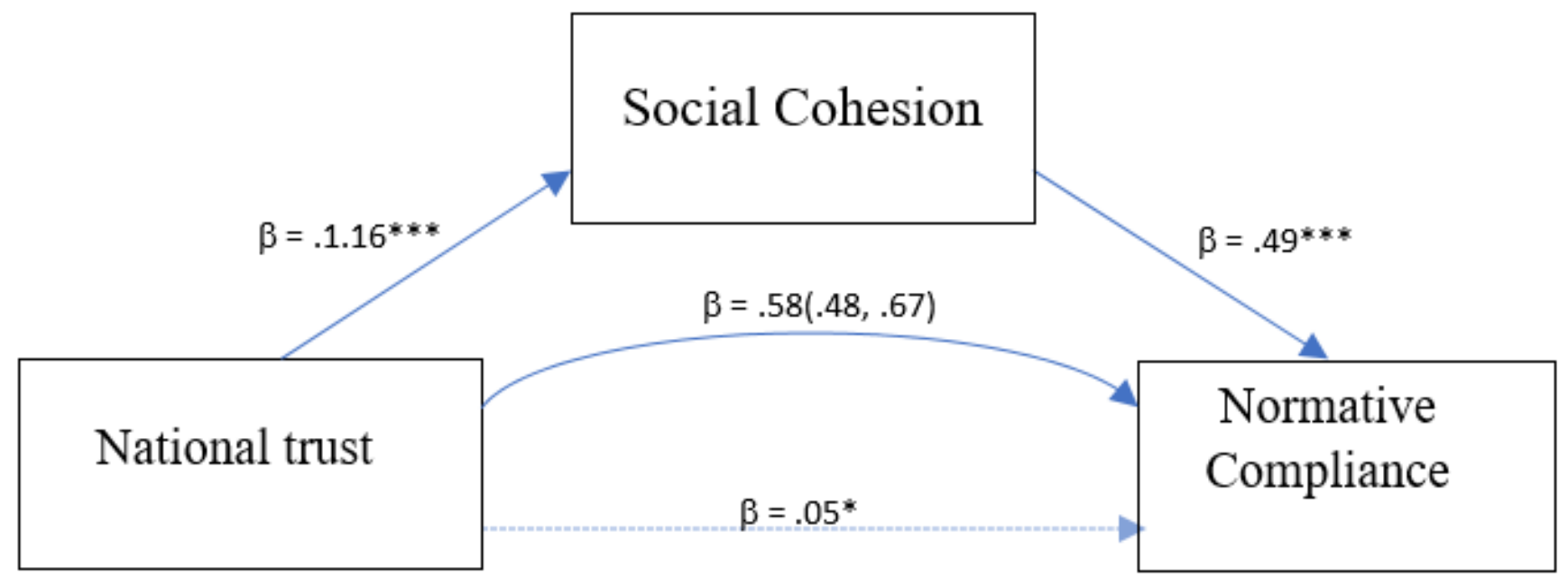

\section{Figure 2}

National trust indirectly predicts normative compliance with COVID-19 via social cohesion. Note. The curved line arrow in the figure represents the hypothesized indirect effect. The total effect of national trust on normative compliance was $\beta=.64, p=.001$. 